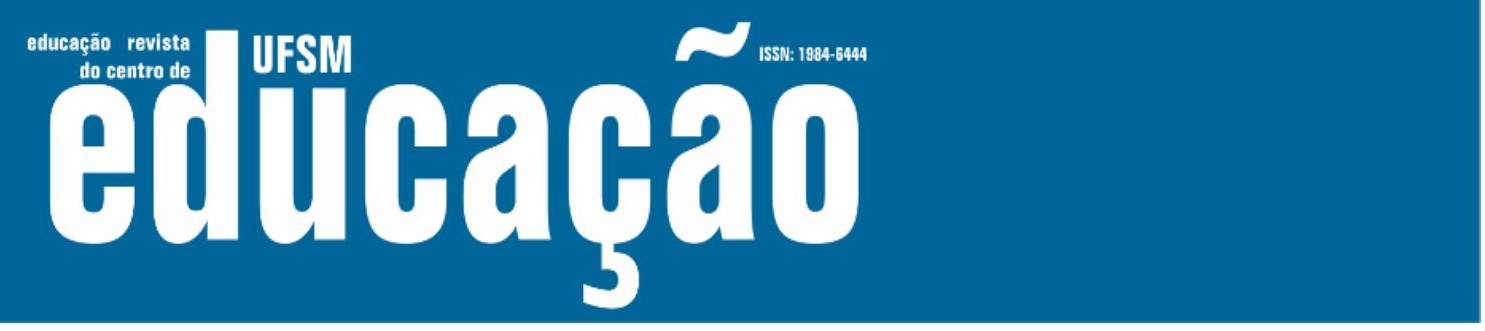

ISSN: 1984-6444 | http://dx.doi.org/10.5902/1984644443284

\title{
Práticas digitais, sexualidade e educação numa escola pública de ensino fundamental
}

Digital practices, sexuality and education in a public middle school

Guilherme Carvalho Franco da Silveira

Professor doutor na Universidade Federal de Minas Gerais. Belo Horizonte, Minas Gerais, Brasil. guilherme.cfs@outlook.com - https://orcid.org/0000-0001-6907-2027

Recebido em 04 de junho de 2020

Aprovado em 05 de junho de 2020

Publicado em 30 de setembro de 2021

\section{RESUMO}

O presente artigo se inspirou na seguinte questão: quais são as práticas digitais relacionadas à sexualidade de adolescentes de 12 a 15 anos de idade, do ensino fundamental? O objetivo foi compreender os usos, os sentidos e as relações sociais que emergem de práticas relacionadas à sexualidade, mediadas pelas mídias digitais de adolescentes de uma escola pública de ensino fundamental de tempo integral. A partir de uma pesquisa de campo de caráter etnográfico, percebeu-se que os/as adolescentes acessam e compartilham, intencionalmente ou não, uma grande quantidade de conteúdo relativo à sexualidade. São discutidas as formas de acesso, as consequências e os conflitos relacionados a tais práticas, além de reflexões sobre tipos de mediação que escola e famílias têm utilizado para lidar com essa questão.

Palavras-chave: Práticas digitais; Adolescentes; Sexualidade.

\section{ABSTRACT}

The present research was inspired by the following question: what is the place of sexuality in the digital practices of middle school adolescents? The objective was to understand the uses, senses and social relations that emerge from practices related to sexuality, mediated by the digital media of adolescents of a public elementary school. From an ethnographic approach, it was noticed that adolescents access and share, intentionally or not (when friends share), a large amount of content related to sexuality. The forms of access, consequences and conflicts that emerged, as well as the types of mediation that school and families used to deal with this issue are discussed.

Keywords: Digital practices; Adolescents; Sexuality. 


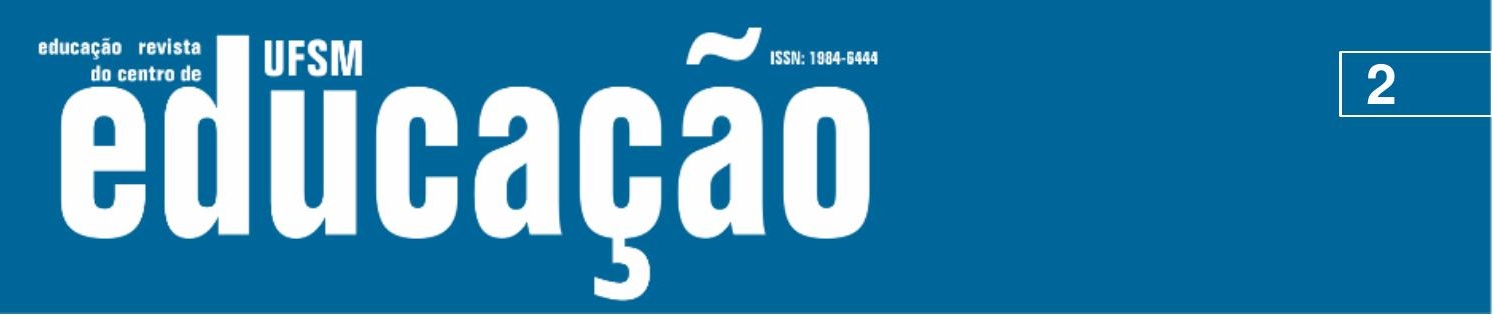

ISSN: 1984-6444 | http://dx.doi.org/10.5902/1984644443284

\section{Introdução}

Este artigo, derivado da pesquisa "Entre celulares, tablets, computadores e consoles: usos e sentidos de práticas digitais no cotidiano de adolescentes"1, se inspirou na seguinte questão: quais são as práticas digitais relacionadas à sexualidade de adolescentes de 12 a 15 anos de idade? O objetivo foi compreender os usos, os sentidos e as relações sociais que emergem de práticas relacionadas à sexualidade, mediadas pelas mídias digitais de adolescentes de uma escola pública de ensino fundamental de tempo integral, da cidade de Belo Horizonte.

A pesquisa se caracterizou como uma etnografia, ou seja, uma escrita sobre as pessoas, que busca uma descrição densa (GEERTZ, 1989), num olhar de perto e de dentro (MAGNANI, 2002). Como afirma Coleman (2010, p. 489), é inegável que as mídias digitais interessam culturalmente, "mas é necessário mostrar como, onde e porque [elas são utilizadas], para confrontar presunções peculiarmente míopes a respeito da universalidade da experiência digital"2.

Assim, a pesquisa de campo, numa escola pública federal, envolveu a observação participante (INGOLD, 2014) das práticas digitais dos cerca de duzentos adolescentes de sétimo, oitavo e nono anos, durante 18 meses (julho/2016 a dezembro/2017), oficinas de práticas digitais, além de um questionário respondido pelos professores desses/as estudantes. A escolha do contexto de estudo foi motivada pela ideia de observar diariamente uma comunidade de adolescentes, em situações em que os dispositivos digitais estivessem presentes. Por ser de tempo integral, a escola selecionada possibilitava um período ampliado de observação dos/as adolescentes em meio a suas práticas digitais. Além disso, uma vez que a entrada de estudantes para essa escola se dá por sorteio, outro motivo relevante da escolha foi a maior diversidade de adolescentes em relação às demais escolas públicas ou particulares. Eram $53 \%$ de alunos sexo masculino e $47 \%$ do feminino. $52,3 \%$ das famílias se percebiam como brancas, $34 \%$ pardas e $4,8 \%$ negras. A distribuição por classes sociais das famílias da escola era a seguinte: classe $A: 5,2 \%$; B: $24,7 \%$, C: $44,8 \%$, e classe D-E: $11,4 \%$. A maioria (58,9\%) dos/as estudantes 


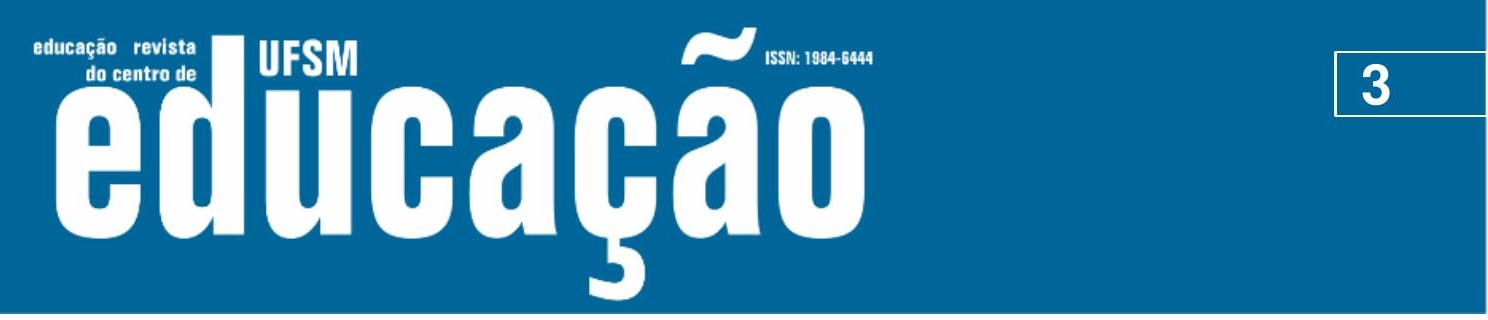

ISSN: 1984-6444 | http://dx.doi.org/10.5902/1984644443284

possuía computador em casa, mas apenas $14 \%$ das famílias tinham acesso a TV a cabo. 4,5\% dos/as alunos/as eram atendidos no programa Bolsa Família (CENTRO PEDAGÓGICO, 2016). Essa diversidade permitiu investigar sujeitos de diferentes classes sociais, etnias, origens culturais e desempenhos acadêmicos.

\section{Adolescentes e práticas digitais relacionadas à sexualidade}

Conforme destaca Louro (2007, p. 210), a sexualidade implica mais do que apenas os corpos das pessoas, relacionando-se a "fantasias, valores, linguagens, rituais, comportamentos, representações mobilizados ou postos em ação para expressar desejos e prazeres". A construção da sexualidade dá-se através de diversas práticas e interações, entre as quais, na contemporaneidade, aquelas atreladas à sedução e ao impacto da mídia, da publicidade, da internet, dos sites de relacionamento (LOURO, 2008). Buckingham (2014, p. 1), por sua vez, entende que "representações sexuais explícitas existiram - ou tiveram que ser suprimidas - em todas as sociedades registradas ao longo da história [...]. Entretanto, a internet claramente permite acesso muito mais fácil a este tipo de material". Nessa mesma direção, Albury (2017, p. 714) afirma que, tanto para adultos quanto para crianças e adolescentes, hoje em dia, cada vez mais,

Novas práticas de representação e interação sexual - como a troca de autorretratos de paquera (selfies), imagens explícitas ou pornográficas e bate-papo sexual - são possibilitadas por uma série de fatores, incluindo a onipresença das culturas de telefones celulares, a popularidade de plataformas de mídia social, como Facebook e Instagram, e a proliferação de sites e aplicativos de namoro/conexão (como o Grindr e o Tinder).

Na escola observada, nudes, sexting, crushes $^{3}$, namoros e pornografia virtuais eram temas constantes nas práticas digitais e nas falas dos/as adolescentes. Questões relativas à sexualidade, mesmo quando iniciadas no ambiente off-line, eram frequentemente amplificadas por tais práticas (ou seja, mais pessoas ficavam sabendo o que se passava, rapidamente), fazendo com que alguns acontecimentos ou conversas banais se transformassem em dramas. Por exemplo, Taciana ${ }^{4}$, uma novata na escola, após contar para algumas amigas quais meninos achava bonitos, 


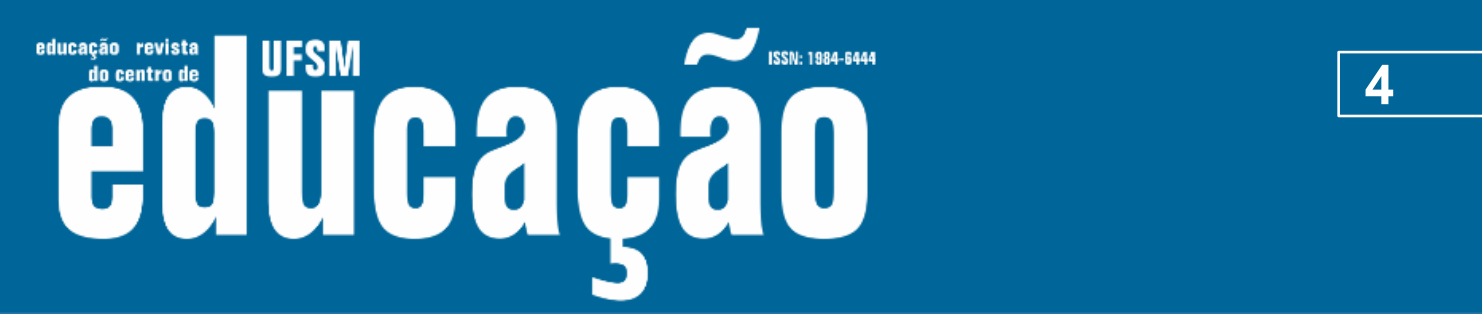

ISSN: 1984-6444 | http://dx.doi.org/10.5902/1984644443284

foi surpreendida por mensagens de WhatsApp que algumas dessas meninas enviaram para os colegas, compartilhando tais comentários. Após as mensagens de WhatsApp serem disparadas, Taciana foi assediada insistentemente nos corredores por alguns dos meninos 'elogiados', que desejavam roubar-lhe um beijo. Apenas após a intervenção da escola, esse assédio terminou. Em outras situações, os/as adolescentes envolvidos (namorados/as, ficantes, crushes etc.) tornavam públicas, no ambiente virtual, suas próprias experimentações com a sexualidade off-line, como no caso a seguir:

\begin{abstract}
Ivy e Amélia me viram no pátio e vieram conversar comigo. "Vai acontecer uma coisa muito interessante na sala do $9^{\circ} \mathrm{B}$, hoje". Ivy disse que a Sabrina havia mandado uma mensagem de texto de WhatsApp para um monte de gente, contando que iria ficar com o Inácio. A Ivy pegou seu celular e me mostrou a conversa dela com a Sabrina. Na conversa, Ivy dizia para a Sabrina que duvidava que ela iria mesmo ficar com o Inácio e a Sabrina respondia garantindo que iria. Mais tarde, Ivy veio me contar que a amiga tinha realmente ficado com o Inácio [Caderno de campo].
\end{abstract}

A troca de material sensual diretamente entre os/as próprios/as adolescentes (especialmente, fotos) era outra prática digital que acontecia com frequência:

\begin{abstract}
Lidiane me mostrou prints do Messenger de uma amiga (cujo nome ela não revelou) em que chamava a atenção um pedido de nudes insistente de um adolescente, que estava sendo negado enfaticamente até aquela data. $O$ menino insistia, enquanto a menina inventava desculpas e se negava a enviar os nudes. Viviane, Cesar, Athena e Ticiana dizem que os homens enviam mais nudes que as mulheres e são também quem mais insiste para receber. Segundo Viviane, se eles têm o pênis grande, "aí é que eles mandam muitos nudes mesmo". Ela diz que para compartilhar coisas ligadas à sexualidade, é preciso saber se é possível confiar ou não no outro e diz que os meninos ficam insistindo e, quando conseguem o nude, "Aí, deixam a menina pra lá" [Caderno de campo].
\end{abstract}

Como destacam Livingstone e Third (2017, p. 663), "o 'sexting adolescente', notavelmente, atraiu um enorme debate sobre a tensão entre direitos de participação e de proteção" desses sujeitos na cultura digital. Segundo essas autoras, até recentemente, era possível manter as práticas sexuais dos/as adolescentes sob o radar da visibilidade pública e da regulação, mas as suas práticas digitais (às quais os adultos dificilmente têm acesso) modificaram esse quadro, uma vez que não há 


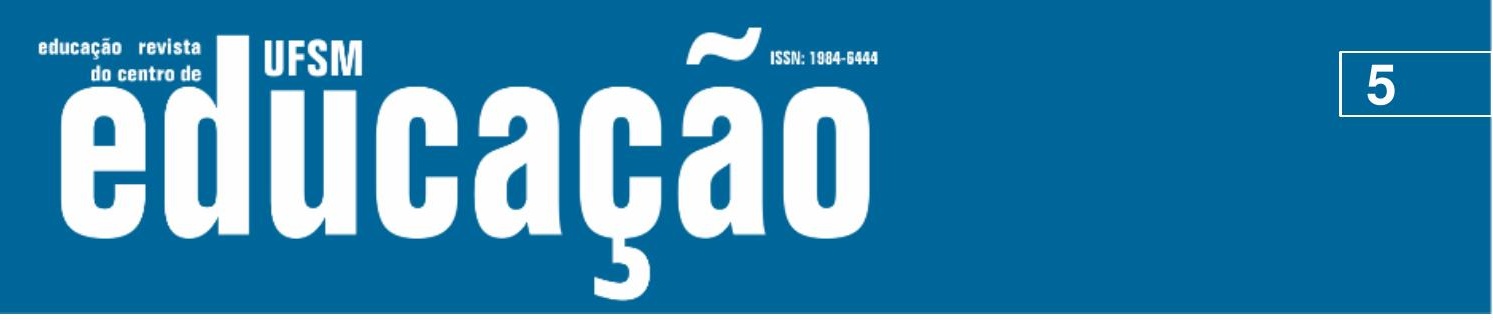

ISSN: 1984-6444 | http://dx.doi.org/10.5902/1984644443284

necessidade de adultos para intermediá-las, como no caso abaixo:

Cynthia me conta (sem citar o nome) sobre uma colega que enviou nudes para o namorado. "Ela só mandou uma vez, mas foi de um segundo e o aplicativo que ela usa [Snapchat] fala se a pessoa tirou print da foto ou não, e o menino não tirou print", ela me diz. "Essa menina confia nele? Não é arriscado?", eu perguntei. "Mais ou menos, ela não o conhece tão bem assim. Ah, mas ele também mandou um nude dele. Se ele tirasse print, ela também iria tirar e mostrar para todo mundo", Cynthia argumentou [Caderno de Campo].

O sexting tem permanecido um assunto quase que restrito aos/às próprios/as adolescentes (LIVINGSTONE; THIRD, 2017), uma vez que a preocupação deles/as não é com possíveis consequências negativas das práticas digitais relacionadas à sexualidade, mas com a possibilidade de serem descobertos e, consequentemente, punidos pelos adultos. Dessa forma, dizem eles/as, muito compartilhamento de imagens e textos acontece sem que pais e professores fiquem sabendo.

A sexualidade digital parecia só sair das sombras quando havia vazamento de imagens e textos, ou quando os pares traíam os/as adolescentes, como no caso de Cibelle. Segundo ela, um amigo ficou sabendo que ela havia enviado nudes para o namorado, "ficou com ciúmes e contou para minha mãe que ficou brava demais, me deu castigo e tomou meu celular por quatro meses". Como nessa situação, a maioria dos/as adolescentes ainda tinha dificuldade de imaginar as possíveis consequências de suas práticas. Apesar dos cuidados, como o uso do Snapchat, já havia na escola pelo menos um caso de nudes vazados de uma aluna (conforme me confidenciou Romero, do oitavo ano). Além disso, houve casos como o de Simone que enviou a um colega, Zeca, um vídeo de si mesma, em nada relacionado à sexualidade, que acabou sendo enviado a um grupo de pornografia on-line. Além do risco e do constrangimento a que Simone foi exposta, pode-se avaliar como também arriscada a atitude de Zeca de participar de um ambiente virtual em que havia adultos, considerando-se a possibilidade de tais pessoas não só constrangerem alguns de seus participantes, mas também de compartilharem imagens de menores de idade (o que teria acontecido, segundo Zeca), caracterizando-se como pedofilia.

Faria, Araújo e Jorge (2016, p. 667), alertam sobre a maior frequência de violação de direitos das mulheres na internet, no Brasil, em relação aos homens: 


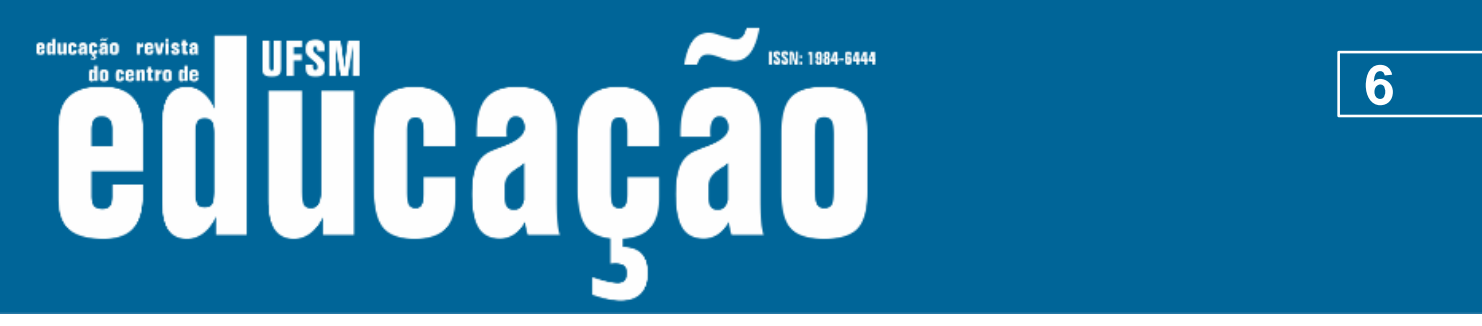

ISSN: 1984-6444 | http://dx.doi.org/10.5902/1984644443284

As denúncias são mais frequentes entre jovens de 13 a 15 anos de idade $(35,71 \%)$ e de 18 a $25(32,14 \%)$. Porém o dado mais relevante para o presente estudo é o recorte de gênero identificado: as mulheres são a maioria das vítimas, correspondendo a $77,14 \%$ dos casos. O que está em jogo nessa prática? Por que os homens são menos afetados por essa exposição? Como as novas tecnologias têm sido utilizadas em novas formas de violência de gênero? Essas são algumas das questões que se colocam de forma cada vez mais contundente aos que pretendem estudar as novas formas midiatizadas de sociabilidade.

Como afirmam Parry e Penny Light (2017), a sexualidade na esfera do lazer digital se apresenta como uma questão mais complexa para as mulheres do que para os homens, uma vez que a cultura digital contemporânea é um contexto em que, apesar de movimentos de resistência, ainda há reprodução de formas discriminatórias e machistas de tratar o gênero e a sexualidade. Lemos e Levy (2014, p. 205) salientam que o atual ambiente tecnocultural é "altamente favorável à diversidade", mas é necessário compreender o lugar às vezes contraditório da mídia digital, cujos "padrões são muito familiares: preconceito, racismo e intolerância são penetrantes" (BOYD, 2014, p. 159). Atitudes machistas se manifestavam, na escola, não apenas nas práticas digitais, foco desse estudo, mas também, segundo algumas alunas, nos corredores em que elas, constrangidas, eram assediadas com olhares e comentários dos meninos.

Albury (2017, p. 722) reflete sobre como as atuais respostas políticas e educacionais ao sexting e ao compartilhamento de nudes por adolescentes poderiam mudar:

\begin{abstract}
E se o direito de uma jovem à participação digital não implicar uma obrigação de (a) manter absoluto sigilo em relação aos seus desejos sexuais ou (b) abster-se inteiramente de todas as formas de expressão sexual mediada? $\mathrm{E}$ se ser conhecido como 'alguém que fofoca e compartilha imagens sexuais sem consentimento' fosse a identidade mais vergonhosa e apresentada aos jovens como tal? E se eles fossem advertidos de que fofocas inapropriadas e compartilhamento de imagens não consensuais são uma violação dos direitos dos outros, que isso poderia prejudicar sua 'reputação' e sua futura empregabilidade? Neste contexto, os direitos positivos de autoexpressão [...] teriam precedência sobre os direitos negativos.
\end{abstract}

Para Albury (2017, p. 714), um problema que emerge da hipocrisia com que se trata a sexualidade das pessoas jovens é que, "quando se nega aos jovens os direitos 


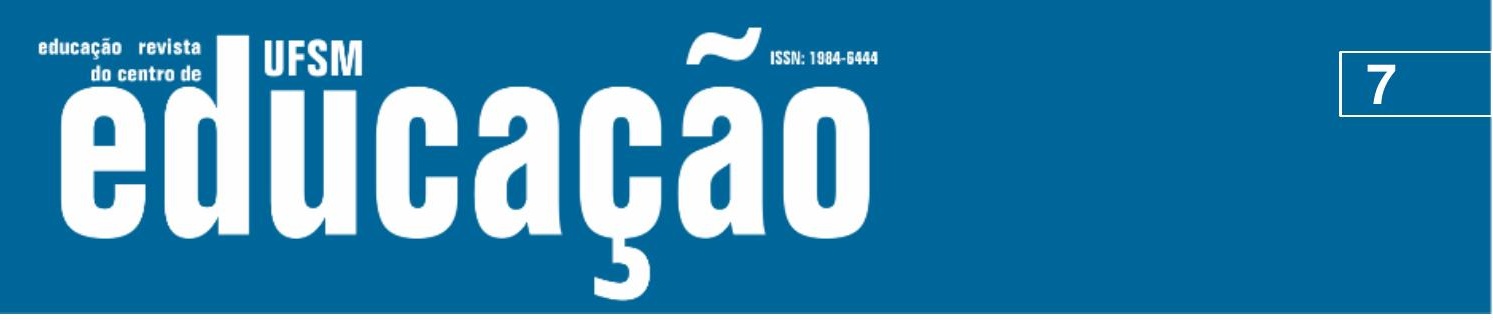

ISSN: 1984-6444 | http://dx.doi.org/10.5902/1984644443284

sexuais (especialmente os direitos à informação sexual e à autorrepresentação sexual), eles/as são excluídos de uma conversa ética". A autora ainda sugere o afastamento das pedagogias que enfatizam a vergonha e o arrependimento quanto à expressão da sexualidade, em direção a uma postura ética em relação às expressões individuais e coletivas dos direitos sexuais na era digital, além da condenação, isso sim, daqueles/as que tornam públicas, sem autorização, informações e imagens privadas (ALBURY, 2017).

Além de tais dilemas, alguns/algumas adolescentes da escola, ainda que não confortáveis com a exposição do próprio corpo, se sentiam pressionados/as a compartilhar nudes e imagens sensuais no intuito de serem aceitos/as por amigos/as, crushes, namorados/as. Nessa direção, Souza e Banaco (2015) chamam a atenção para o drama do sexting como uma ação de autoafirmação de adolescentes, tendo em vista a pressão do grupo social e as exigências para serem aceitos por colegas. Para Le Breton (2012), o sentimento de identidade dos/as adolescentes, apesar de parecer assegurado, irrefutável, "está sempre sob a ameaça do olhar dos outros ou dos acontecimentos da história pessoal" o que ajuda a compreender a submissão de alguns dos sujeitos observados à influência dos pares.

Foi possível notar ainda que as trocas de mensagens, fotos e vídeos de conteúdo sexual, através de aplicativos de mensagens e sites de redes sociais, aconteciam mesmo entre adolescentes distantes, que pouco se conheciam, como o trecho do caderno de campo a seguir ilustra:

\footnotetext{
Lídia me mostra, no Whatsapp, uma conversa com um adolescente uruguaio que ela conheceu em uma festa e com quem havia "ficado",dizendo que, mesmo após voltar ao Uruguai, ele continuava conversando com ela. $\mathrm{Na}$ conversa, ela pergunta: "Você já se masturbou hoje?" e ele responde "Sim, como todo jovem da sua idade". As colegas de Lídia se divertem com a espontaneidade da amiga e a provocam a mostrar também a conversa virtual entre ela e uma outra adolescente de quem ela gosta. Ela não se importa e mostra a conversa, toda ela de caráter sexual, com insinuações de Lídia sobre fazer sexo com a menina. Joana comenta que sua mãe perguntou se ela não tinha medo de a Lídia se interessar por ela também. Joana disse que explicou quem era Lídia, seus interesses, que eram apenas amigas e que não havia por que a mãe se preocupar [Caderno de campo].
} 


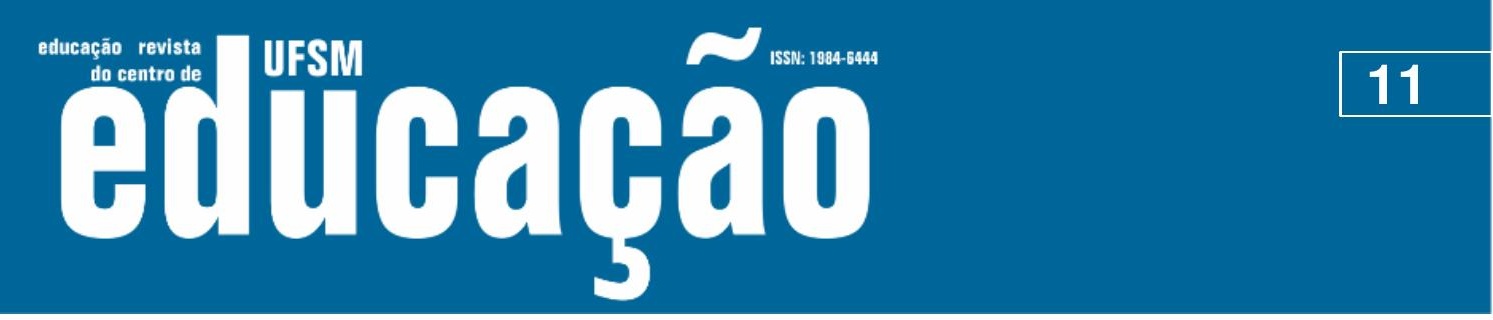

ISSN: 1984-6444 | http://dx.doi.org/10.5902/1984644443284

Brenda avaliava, no Facebook, os meninos que lhe interessavam. "Esse é gato... Esse não...", me mostrando as fotos. Eu pergunto se ela conhece todos e ela diz que sim. Alguns ela conheceu no Facebook e, posteriormente, para ter certeza de quem era, os adicionava no WhatsApp, conversava por mensagem de texto e, então, fazia chamadas de vídeo. Ela salienta que, só depois desse processo, é que se encontrava com eles presencialmente [Caderno de campo].

Essa estratégia de iniciar um relacionamento virtualmente, continuá-lo em outros modos virtuais, partir para a chamada de vídeo para, então, confirmando-se o interesse, acontecer o encontro presencial, apareceu em diversos relatos dos sujeitos da pesquisa e é denominada de "mudança de modalidade" por Sprecher e Hampton (2016). Segundo os/as adolescentes, tal estratégia permitia conhecer melhor as pessoas e, também, certificar-se de que elas eram realmente (em termos físicos) como nas imagens de seus perfis. Alguns/algumas também diziam que tal estratégia ajudava a evitar encontrar gente perigosa ou adultos se passando por jovens. Ariadne ainda citou uma estratégia adicional de cuidado: quando resolvia se encontrar com seus crushes virtuais, ela levava a mãe para o local de encontro, como um shopping. Ela, então, dizia para a mãe onde se encontraria com o menino e que, se ligasse em cinco minutos, é porque "queria sair fora do cara", esperando que a mãe fosse ao encontro dela.

Esse é um interessante exemplo de mediação parental ${ }^{6}$ (VALKENBURG et al, 2013), muito pouco citado pelos/as adolescentes na pesquisa, que indica cuidado da mãe com as práticas digitais da filha e o seu respeito ao desejo complexo, mas não contraditório, da adolescente "de manter conexões próximas com os pais, bem como a necessidade de se estabelecer como um indivíduo autônomo" (MCELHANEY et al., 2009, p. 358), fruto de uma relação, provavelmente, baseada na confiança e no diálogo.

Os/as adolescentes, por outro lado, afirmavam que nem todas as relações iniciadas virtualmente eram levadas à frente para outras modalidades de comunicação, exatamente porque, à medida que o relacionamento avançava por diferentes sites de redes sociais e aplicativos de mensagens, eles/as percebiam que nem todas as pessoas que conheciam virtualmente interessavam-lhes presencialmente. Muitas 'amizades' no Facebook ou Instagram ficavam por lá mesmo, 


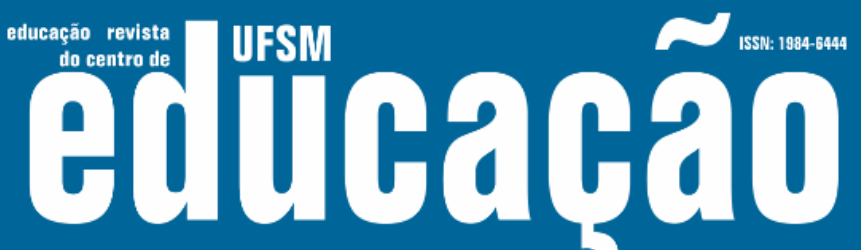

ISSN: 1984-6444 | http://dx.doi.org/10.5902/1984644443284

aproximar os/as adolescentes das práticas digitais relacionadas à sexualidade.

Ainda assim, vários adultos tratam como inaceitáveis quaisquer sinais de práticas digitais de adolescentes ligadas à sexualidade, como no caso de Cidinha, que me confidenciou, após seu pai descobrir um pedido de nudes (negado por ela): "Ele me tomou o celular, vendeu o que me daria no Natal, me proibiu de ver TV por três meses e disse que o celular que eu vou usar de agora em diante será vigiado por ele o tempo todo".

\section{Práticas digitais, sexualidade e educação}

Apesar de reações como a do pai de Cidinha (que passou a fazer práticas digitais em celulares de colegas), a pesquisa apresentou evidências de que a sexualidade digitalmente mediada, era uma prática central na vida de vários/as adolescentes, tanto em casa quanto na escola. Tais evidências reforçam a ideia de que, os/as adolescentes não se tornam sujeitos sexuados de repente, na idade permitida pela legislação (dezoito anos, no Brasil), mas passam por um processo de experimentação e conscientização com a sexualidade no qual "a troca de mensagens e imagens sexualizadas poderia ser vista como um 'risco menor' do que a atividade sexual face a face entre os jovens envolvidos" (MCLELLAND, 2017, p. 7).

Existe, na literatura, uma tensão entre os defensores dos direitos de expressão sexual, e os que enfatizam a necessidade de proteção contra experiências on-line potencialmente perigosas (SOUZA; BANACO, 2018). Uma vez que estão em intenso contato com a sexualidade on-line, a formação crítica dos/as adolescentes, o entendimento das possibilidades e dos limites (inclusive legais) para viver a sexualidade e a compreensão das possíveis consequências de suas experimentações virtuais tornam-se relevantes.

Não há dúvidas de que jovens encontrarão formas de contornar possíveis restrições de acesso à sexualidade digital (BUCKINGHAM, 2014), motivo pelo qual a mediação dos adultos precisa ir além do estabelecimento de proibições ou do silêncio, que "é uma forma de comunicação que acaba alimentando censuras e tabus" e intensificando preconceitos na vivência da sexualidade" (GONÇALVES; GODOI, 


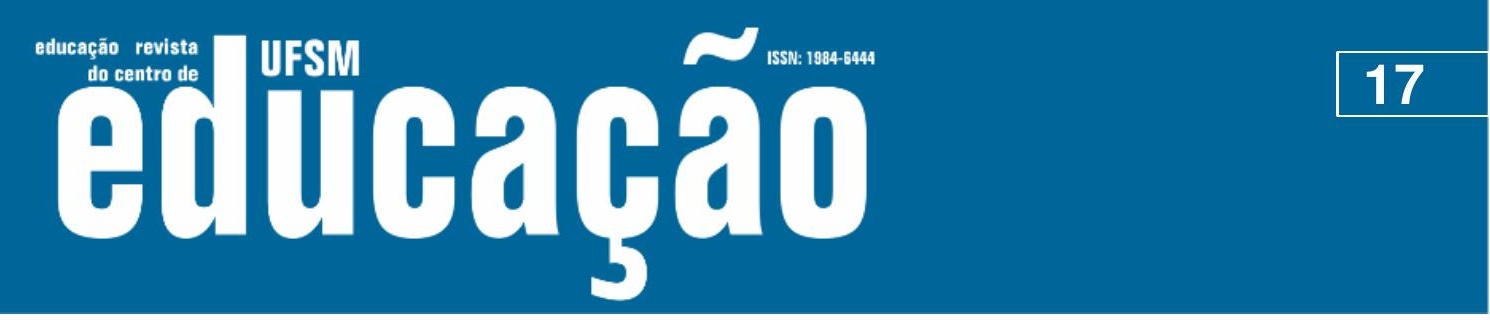

ISSN: 1984-6444 | http://dx.doi.org/10.5902/1984644443284

intencionalmente ou não, expressam pedagogias da sexualidade. Livingstone e Third (2017, p. 663) nos convidam a pensar no problema de que, para adolescentes, a educação para "a expressão sexual on-line é amplamente formulada através de 'pedagogias de vergonha e arrependimento', como evidenciado pelo crescimento dos currículos de segurança eletrônica sobre sexting", num movimento que enfatiza excessivamente a proteção, deixando à margem as estratégias de formação crítica. Para Nejm (2016, p. 55), a questão da sexualidade digital dos/as adolescentes é extremamente complexa, uma vez que,

\begin{abstract}
Dentro de uma perspectiva de proteção integral, ainda há uma compreensão hierarquizada dos três "Ps" [provisão, proteção e participação] quando se discute a sexualidade de crianças e adolescentes, na medida em que a proteção vem quase sempre em primeiro lugar ou é confundida como sendo sinônimo dos direitos sexuais como um todo. O fenômeno dos nudes revela, de forma emblemática, um campo de tensionamento entre: direito à proteção contra violações da dignidade sexual; acesso à informação e educação sexual; e oportunidades de livre opinião e expressão da sexualidade.
\end{abstract}

Assim, tratar a relação práticas digitais-sexualidade apenas numa perspectiva proibicionista restringe a formação dos sujeitos, pois, como salientam Cunha e Nejm (2017, p. 55),

\begin{abstract}
Quando o assunto envolve a prática do envio e recebimento de nudes e jogos sexuais entre pares, via de regra esses fenômenos são encarados sob a ótica dos riscos, em detrimento de uma agenda mais positiva. São pouco citados aspectos como a provisão de acesso à educação sexual; o empoderamento de meninas e mulheres para promoção de relações com maior equidade de gênero; garantia de conteúdos e espaços digitais apropriados às dúvidas e demandas de crianças e adolescentes sobre seus direitos sexuais; recursos de mediação de conflitos com participação de adolescentes; conscientização sobre liberdade sexual feminina para combater a culpabilização e revitimização de meninas expostas.
\end{abstract}

Mesmo indesejado, o compartilhamento de pornografia e de fotos sensuais dentro da escola era percebido por vários/as adolescentes como algo banal, nada extraordinário, além de desconhecerem as consequências negativas de algumas dessas práticas. A transgressão significou que essas consequências não puderam ser devidamente problematizadas pela escola junto aos/às adolescentes, uma vez que aconteciam dissimuladamente (já que se imaginava ter erradicado o problema com a 


\section{OF LFH oltuarao

ISSN: 1984-6444 | http://dx.doi.org/10.5902/1984644443284

Se, por um lado, a ampliação das oportunidades de práticas digitais, garantindo-se os direitos de provisão e participação, pode gerar maior exposição dos/as adolescentes a riscos (incluindo, mas não se limitando àqueles relacionados à sexualidade), o que obviamente se deseja evitar, por outro lado "são também os usuários mais experientes e engajados há mais tempo que demonstram maiores habilidades para minimizar possíveis efeitos negativos de situações vivenciadas online" (CGI.BR, 2017, p. 95).

A proibição do wi-fi e o desconhecimento da escola a respeito das práticas digitais apenas provocava o 'esquecimento' da questão da sexualidade digital e incentivava a criação de possibilidades de transgressão, diminuindo a quantidade de adolescentes que realizavam práticas diretamente em seus celulares (mas, aumentando, consequentemente, o número dos/as que acompanhavam essas práticas nos dispositivos de colegas que tinham 3G/4G). Nesse contexto, a escola, apesar de não fazer qualquer distinção quanto ao cumprimento das normas, acabava sendo mais um palco "da reprodução social da desigualdade, apesar de professar “justiça'” (LIVINGSTONE; SEFTON-GREEN, 2016, n.p.), relegando a formação para a sexualidade e o letramento digital dos/as adolescentes a segundo plano (o que significa que aqueles/as em condições socioeconômicas desfavoráveis eram potencialmente os/as mais prejudicados/as).

Enfim, em vez de apenas tentar restringir as práticas digitais relacionadas à sexualidade, é necessário, como destaca Buckingham (2014, p. 6), que a escola promova "uma discussão mais aberta e sensata sobre essas questões, na qual crianças e adolescentes tenham a oportunidade de participar" da reflexão sobre a própria sexualidade e da construção de princípios e estratégias para a sua formação. Nesse sentido, letramento digital e educação para a sexualidade parecem questões urgentes sobre as quais a escola precisa se debruçar para pensar a formação de adolescentes para além do currículo formal. Simplesmente censurar, demonizar ou (imaginar) proibir as práticas digitais, não vai afastar delas os/as adolescentes, nem os/as ajudar a navegar mais crítica e competentemente na cultura digital, na sexualidade e no mundo contemporâneo. 


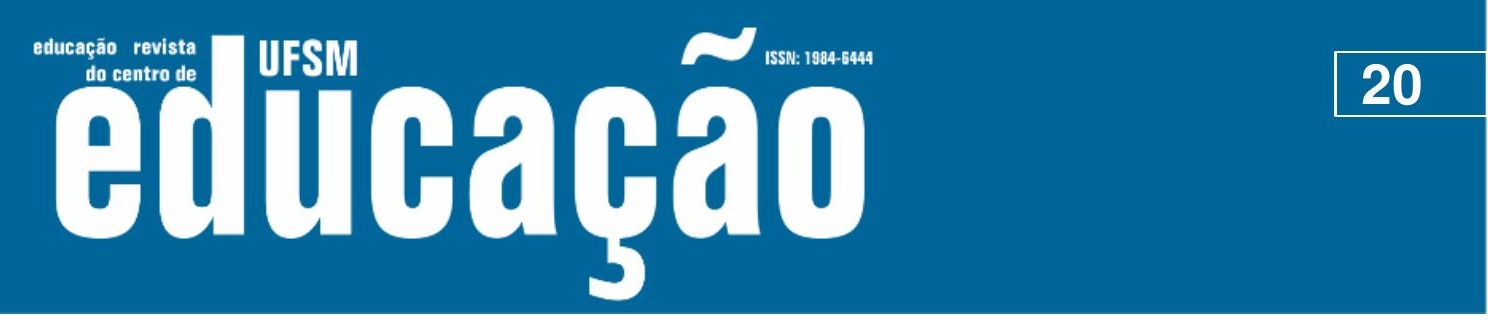

ISSN: 1984-6444 | http://dx.doi.org/10.5902/1984644443284

\section{Referências}

ALBURY, Kath. Just because it's public doesn't mean it's any of your business: adults' and children's sexual rights in digitally mediated spaces. New Media and Society, v. 1, n. 13, 2017.

BOYD, Dana. Social network sites as networked publics: affordances, dynamics, and implications. In: PAPACHARISSI, Zizi (ed.). A networked self. Routledge, p. 47-66, 2010.

BOYD, Dana. It's complicated: the social lives of networked teens. New Haven: Yale University Press, 2014.

BRASIL. Lei 12.965 de 23 de abril de 2014. Estabelece princípios, garantias, direitos e deveres para o uso da Internet no Brasil. Dário Oficial da República Federativa do Brasil, Brasília, 22 abr. 2014.

BUCKINGHAM, David. Objectionable content? Young people, censorship and pornography. Londres: [s.n.], 2014. Disponível em: https://www.academia.edu/7453955/Objectionable_content_Young_people_censorsh ip_and_pornography. Acesso em: 26 abr. 20198.

BUCKINGHAM, David; BURN, Andrew. Game literacy in theory and practice. Journal of Educational Multimedia and Hypermedia, v. 16, n. 3, p. 323, 2007.

CENTRO PEDAGÓGICO. Planejamento Pedagógico do Convênio - Programa Segundo Tempo. Belo Horizonte: CP, 2016

CLARK, Lynn S. Parental mediation theory for the digital age. Communication Theory, v. 21, n. 4, p. 323-343, 2011. Disponível em: http: //10.1111/j.14682885.2011.01391.x. Acesso em: 27 mar. 2019.

COLEMAN, Gabriella. Ethnographic approaches to digital media. Annu. Rev. Anthropol. v. 39, p. 487-505, 2010.

COMITÊ GESTOR DA INTERNET NO BRASIL - CGI.br. TIC Kids Online Brasil 2016: pesquisa sobre o uso da Internet por crianças e adolescentes no Brasil. São Paulo: CGI.br, 2017. 


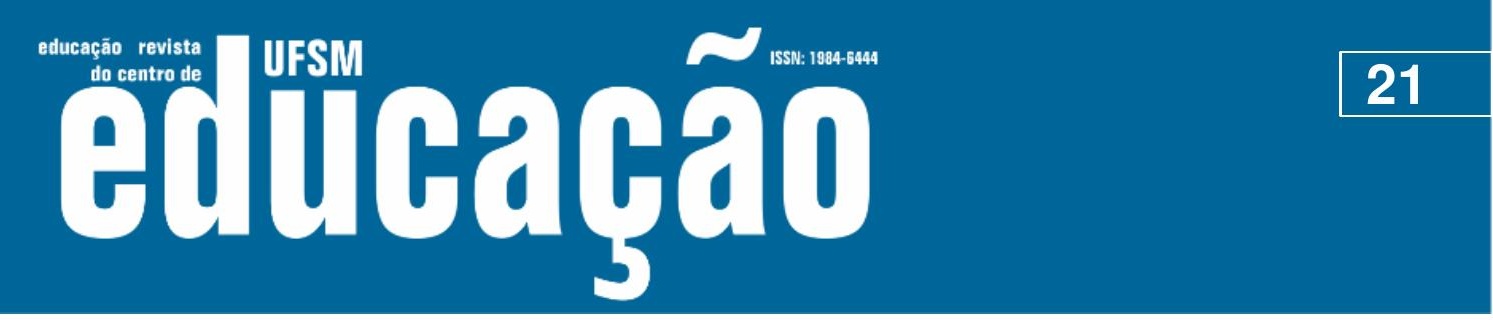

ISSN: 1984-6444 | http://dx.doi.org/10.5902/1984644443284

CUNHA, Juliana; NEJM, Rodrigo. "Manda nudes": oportunidades e riscos relacionados aos direitos sexuais de crianças e adolescentes na internet. In: COMITÉ GESTOR DA INTERNET NO BRASIL - CGI.br. TIC Kids Online Brasil 2016: pesquisa sobre o uso da Internet por crianças e adolescentes no Brasil. São Paulo: CGI.br, 2017.

DE BARROS, Suzana da Conceição; RIBEIRO, Paula Regina Costa; QUADRADO, Raquel Pereira. Sexting na adolescência: problematizando seus efeitos no espaço escolar. Perspectiva, Florianópolis, v. 33, n. 3, p. 1185-1204, 2015.

DORES, António Pedro. Proibicionismo e anomia: uma apresentação do conceito (Prova de Agregação). Lisboa: Instituto Universitário de Lisboa, 2003. Disponível em: https://repositorio.iscte.pt/handle/10071/6799. Acesso em 28 abr. 2018.

FARIA, Fernanda Cupolillo Miana de; ARAÚJO, Júlia Silveira de; JORGE, Marianna Ferreira. Caiu na rede é porn: pornografia de vingança, violência de gênero e exibição da "intimidade". Contemporanea - Revista de Comunicação e Cultura, Salvador, v. 13, n. 3, p. 659-677, 2016.

GEERTZ, Cliford. A interpretação das culturas. Rio de Janeiro: LTC, 1989.

GONÇALVES, Betânia Diniz; GODOI, Claudia Mayorga Borges de. Sexualidade e afetividade In: CARVALHO, A; SALLES, F.; GUIMARÃES, M. Adolescência. Belo Horizonte: Editora UFMG, 2003.

INGOLD, Tim. That's enough about ethnography! Hau: Journal of Ethnographic Theory, vol 4, n. 1, p. 383-395, 2014.

KAUFMAN, Dora. A força dos "laços fracos" de Mark Granovetter no ambiente do ciberespaço. Galáxia, n. 23, p. 207-218, jun. 2012

LEMOS, André; LEVY, Pierre. O futuro da internet: em direção a uma ciberdemocracia planetária. São Paulo: Paulus, 2014.

LE BRETON, David. O risco deliberado: sobre o sofrimento dos adolescentes. Política \& Trabalho, João Pessoa, n. 37, 2012.

LIVINGSTONE, Sonia; SEFTON-GREEN Julian. The Class: Living and Learning in the Digital Age. New York: New York University Press, 2016. Disponível em: http://hdl.handle.net/2333.1/73n5tfjs. Acesso em: 8 nov. 2018.

LIVINGSTONE, Sonia; THIRD, Amanda. Children and young people's rights in the digital age: An emerging agenda. New Media \& Society. vol. 19, n. 5, p. 657-670, 2017. 


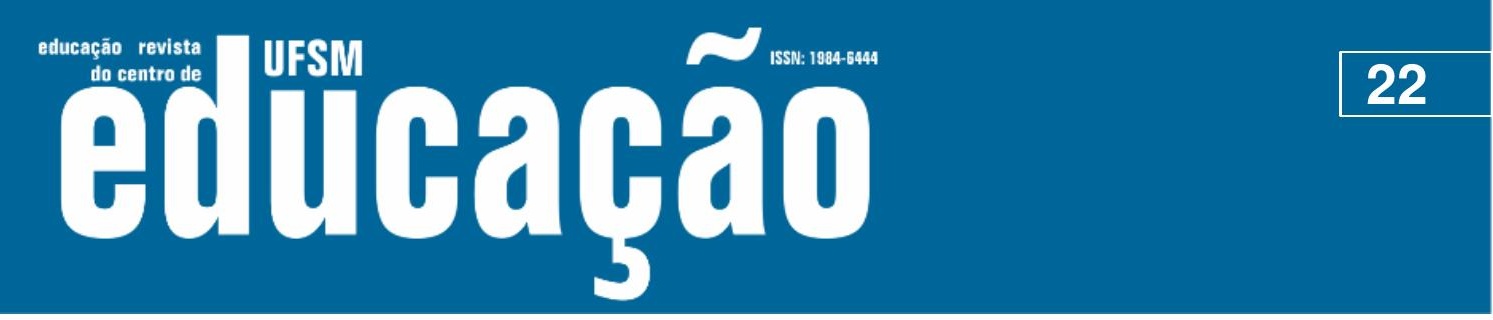

ISSN: 1984-6444 | http://dx.doi.org/10.5902/1984644443284

LOURO, Guacira Lopes. Gênero, sexualidade e educação: das afinidades políticas às tensões teórico-metodológicas. Educação em Revista. Belo Horizonte, n. 46, p. 201 218, dez. 2007.

LOURO, Guacira Lopes. Gênero e sexualidade: pedagogias contemporâneas. ProPosições, vol. 19, n.2, Campinas, mai/ago., 2008.

MAGNANI, José Guilherme Cantor. De perto e de dentro: notas para uma etnografia urbana. Revista Brasileira de Ciências Sociais, São Paulo, v. 17 n. 49, jun. 2002.

MCELHANEY, Kathleen Boykin et al. Attachment and autonomy during adolescence. Handbook of adolescent psychology. In: LERNER, Richard M.; STEINBERG, Laurence (ed). Handbook of Adolescent Psychology. New Jersey: John Wiley \& Sons Inc., 2009.

MCGILLIVRAY, David et al. Young people, digital media making and critical digital citizenship. Leisure Studies, v. 35, n. 6, p. 724-738, 2015. Disponível em:

https://www.tandfon-line.com/doi/abs/10.1080/02614367.2015.1062041. Acesso em: 24 set. 2018.

MCLELLAND, Mark. 'Not in front of the parents!': young people, sexual literacies and intimate citizenship in the internet age. Sexualities, v. 20, n. 1-2, p. 234-254, 2017.

MITRA, Sugata; RANA, Vivek. Children and the Internet: experiments with minimally invasive education in India. British Journal of Educational Technology, v. 32, n. 2, p. 221-232, 2001.

NEJM, Rodrigo. Exposição de si e gerenciamento da privacidade de adolescentes nos contextos digitais. 2016, $266 \mathrm{f}$. Tese (Doutorado em Psicologia) - Programa de Pós-Graduação em Psicologia, Universidade Federal da Bahia, Salvador, 2016.

PARRY, Diana C.; PENNY LIGHT, Tracy. Sexual desire in the digital leisure sphere: women's consumption of sexually explicit material In. CARNICELLI, Sandro et al. Digital leisure cultures: critical perspectives. New York: Routledge, 2017.

PRZYBYLSKI, Andrew K.; NASH, Victoria. Internet filtering and adolescent exposure to online sexual material. Cyberpsychology, Behavior, and Social Networking, v. 21, n. 7, p. 405-410, 2018.

SOUZA, Fabricio de; BANACO, Roberto Alves. A Prática Cultural do Sexting entre Adolescentes: Notas para a Delimitação do Objeto de Estudo. Acta Comportamentalia: Revista Latina de Análisis del Comportamiento, v. 26, n. 1, 2018. 


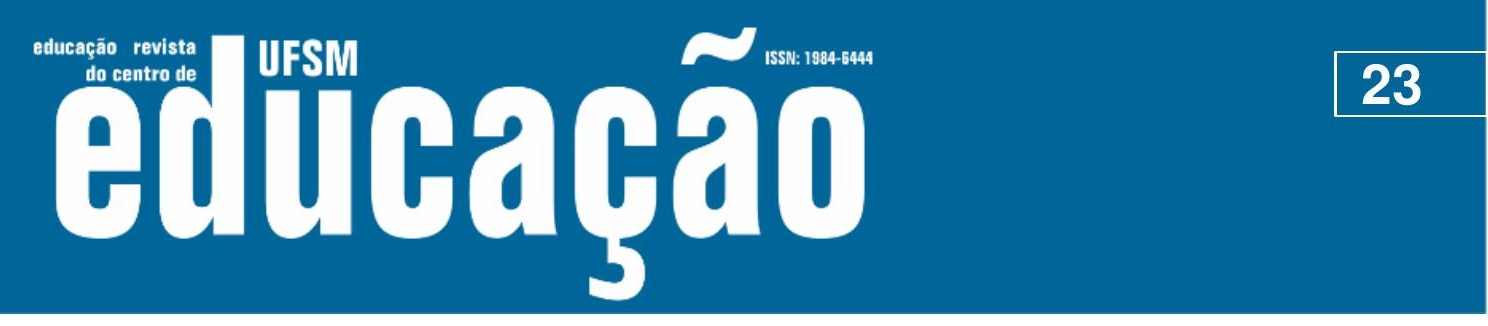

ISSN: 1984-6444 | http://dx.doi.org/10.5902/1984644443284

SPRACKLEN, Karl. Digital leisure, the internet and popular culture: communities and identities in a digital age. New York: Palgrave MacMillan, 2015.

SPRECHER, Susan; HAMPTON, Adam J. Liking and Other Reactions After a GetAcquainted Interaction: a Comparison of Continuous Face-to-Face Interaction versus Interaction that Progresses from Text Messages to Face-to-Face. Communication Quarterly, v. 65, n. 3, p. 333-353, 2016.

VALKENBURG, Patti M. et al. Developing and validating the perceived parental media mediation scale: a self-determination perspective. Human Communication Research, v. 39, n.4. p. 445-469, 2013.

\title{
(@) $(1 \otimes$
}

This work is licensed under a Creative Commons Attribution-NonCommercial 4.0 International (CC BY-NC 4.0)

\section{Notas}

\begin{abstract}
${ }^{1}$ A pesquisa foi aprovada pelo Comité de Ética em Pesquisa da UFMG. Pais e estudantes assinaram, respectivamente, Termo de Consentimento Livre e Esclarecido e Termo de Assentimento Livre e Esclarecido, em que eram informados de que a participação na pesquisa era facultativa e de que poderiam se retirar a qualquer momento, sem necessidade de explicitar os motivos. Escola e/ou famílias eram comunicadas de situações a que tive acesso e que exigiam intervenção imediata.
\end{abstract}

${ }^{2}$ Todos os trechos que, como este, estão em inglês ou espanhol, no original, foram traduzidos por mim e serão apresentados apenas na versão traduzida.

${ }^{3}$ Nudes é uma palavra que se refere a imagens de nudez e ao seu compartilhamento. Sexting é o termo que resulta da fusão de duas palavras em inglês: sex (sexo) e texting (envio de mensagens) e que designa a produção e o compartilhamento, por meio digital, de imagens ou textos de conteúdo sexual, que expressem experiências e/ou insinuações sexuais (SOUZA; BANACO, 2018). Crush (plural crushes) pode ser definido como uma paixão geralmente breve e intensa por alguém.

${ }^{4}$ Todos os nomes de pessoas neste texto são fictícios, para proteger a identidade dos sujeitos da pesquisa.

5 Pânico moral entendido como a "ansiedade 'improdutiva' com a qual os pais, os professores, os operadores do direito e até estudiosos da adolescência muitas vezes [se] expressam reproduzindo preconceitos, limitando debates e dificultando a aquisição de repertórios de autonomia e responsabilidade" (SOUZA; BANACO, 2018, p. 138).

${ }^{6}$ Segundo Valkenburg et al. (2013), as estratégias de mediação quanto ao uso das mídias digitais podem ser classificadas em: a) restritiva (regras para restringir o tempo de tela ou os conteúdos); b) ativa (explicação dos conteúdos das mídias); e c) compartilhada (uso das mídias junto com os/as adolescentes, sem reflexão sobre os seus conteúdos). Clark (2011) ainda cita outra estratégia, a aprendizagem participativa, semelhante à mediação ativa, mas com uma ênfase particular no diálogo iniciado a partir da perspectiva dos/as adolescentes. 


\title{
ussm Ellloahă
}

ISSN: 1984-6444 | http://dx.doi.org/10.5902/1984644443284

\begin{abstract}
${ }^{7}$ Marco Civil da Internet (Lei $N^{\circ} 12.965 / 14$ ) é a lei que regula o uso da Internet no Brasil assim como estipula diretrizes para a atuação do Estado com relação a ela.

${ }^{8}$ Buckingham e Burn (2007) entendem o letramento digital em três dimensões: a) funcional (habilidade de operar a tecnologia e seus respectivos softwares); b) crítica (análise, avaliação e crítica dos contextos sociais, econômicos, políticos e institucionais de uma tecnologia em particular, e a compreensão de como isso afeta a vida das pessoas) e c) criativa (imersão, prazer, sensibilidade e produção cultural relacionadas a uma dada tecnologia)
\end{abstract}

9 Proibicionismo é um termo geralmente mais associado às proibições relativas ao consumo de drogas, mas que também pode ser estendido a outros campos, como o da cultura digital, e que pode ser entendido como o insistente "exercício de poder para enfrentar o que não se entende, por imposições de força desproporcionada, com vista a obter transformação de comportamentos de terceiros, de forma imediata e sem outro tipo de investimentos suplementares" (DORES, 2003, p. 11). 